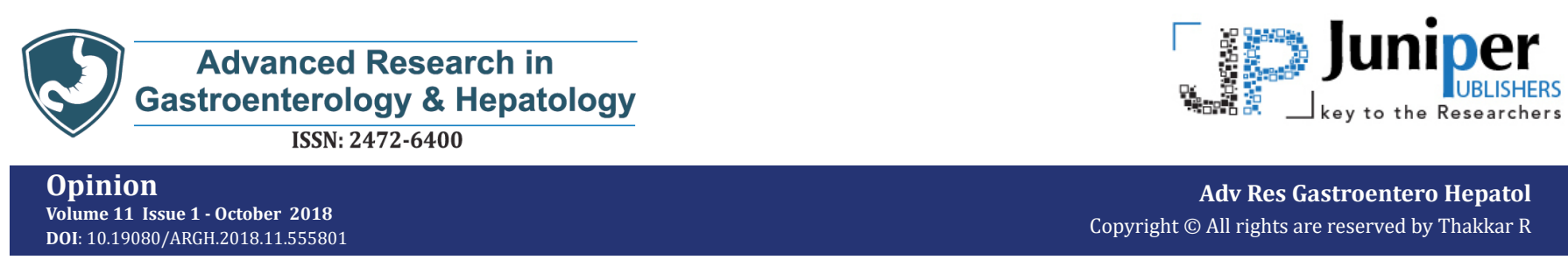

\title{
What Should be the Extent of Liver Resection for pT1b \& pT2 Gall Bladder Cancers?
}

\author{
Thakkar R*, Kanwar A, Alessandri G, Hammond J, Wilson C, Sen G, French JJ, White SA and Manas D \\ Department of HPB and transplant surgery, Freeman hospital, UK
}

Submission: September 19, 2018; Published: October 04, 2018

"Corresponding author: Thakkar R, Department of HPB and transplant surgery, Freeman hospital, Newcastle upon Tyne, UK, Email: Rohan.Thakkar@nuth.nhs.uk

Keywords: Biliary tract; Gall bladder cancer; Surgery; Liver, Tendency; Lymphadenectomy

Abbreviations: GBCA: Gall Bladder Cancer; ESMO: European Society of Medical Oncology; LN: Lymph Node; T1: T-stage

\section{Introduction}

Gall bladder cancer (Gbca) is the commonest cancer of the biliary tract [1]. It has a variable prevalence worldwide. Chile has an incidence as high as 7.5 per 100000 population, especially in American Indian females [2].

There is no effective treatment for gall bladder surgery except for surgery. It has a propensity for early lymph node metastases and direct invasion into the liver, and a tendency to seed the peritoneal cavity, biopsy tracts, and laparoscopic port sites. The overall 5-year survival rate is 5\%-42.3\%, even after radical resection of the tumour [3]. Surgical management for gallbladder cancer is variable and ranges of different operations are undertaken for the disease in different centers. This varies from simple cholecystectomy to extended liver resection with resection of common bile duct and lymphadenectomy [4]. The prognosis for patients with early GBCa, defined as pT1a/b lesions, shows a 5-year survival rate of $82 \%-100 \%$ [5]. The currently recommended treatment guidelines for GB cancer according to the European Society of Medical oncology (ESMO) include resection of at Segment IVB and V with portal lymph node (LN) dissection [6].

\section{Discussion}

There are two major issues that must be addressed when considering the optimal operation for gallbladder cancer, namely the extent of hepatic resection and the extent of the regional lymphadenectomy. The benefit of aggressive resection in early T-stage (T1) tumours that invade the muscularis remains a matter of some debate [7].

It is well established that for T1a tumours a simple cholecystectomy will suffice provided the resection margin is not involved, but there is some ambiguity in the management of T1b tumour. Some authors believe that T1b tumours should be considered as a localised disease because, perineural and lymphovascular invasion are rarely seen, and extended cholecystectomy does not improve the long-term survival in these patients. Whereas others believe pT1b GB cancer recurs more frequently than pT1a GB cancer and an extended cholecystectomy increases the long-term survival rate of patients with pT1b GB cancer [8]. Shirai et al. [9] reported 39 patients with Stage I cancers treated by simple cholecystectomy with a 100\% 5-year survival rate. In a series of variously associated major surgical procedures, including biliary tract resection, major hepatectomy, pancreaticoduodenectomy and major colon surgery, performed for GB cancer, it was concluded that simple cholecystectomy is curative for stage I patients. An analysis done by Abramson et al suggested better survival for pT1b tumour that underwent a radical resection, but this analysis had its limitations [10].

Loco-regional lymph nodes are disposed along the main arteries and include the cystic duct, pericholedochal, hilar (hepatoduodenal ligament, inferior caval vein), peripancreatic (head), peri duodenal, periportal, coeliac, superior mesenteric and para-aortic lymphatic chains [11]. Wakai et al. [12] concluded that there was no survival benefit for performing a radical resection for T1b tumours, considering the morbidity and mortality rate of radical resections. In a multicentre Japanese study of 1686 patients resected for gallbladder cancer: the rate of lymph node metastases was $2.5 \%$ in 201 patients with a pT1a tumour but increased to $15.5 \%$ in 165 patients with pT1b tumours.

The surgical management of T2 GBCa remains controversial. In these patients, the appropriateness of simple cholecystectomy versus radical resection remains the subject of debate. Some groups believe that most $\mathrm{T} 2$ lesions require only simple 
cholecystectomy, thus contending that radical resection is unnecessary and should be reserved for only a small subset of patients who meet certain pathological criteria. On the other hand, proponents of radical resection believe that all T2 lesions should be treated with radical resection, because $40 \%$ of these patients will have residual lymphatic disease after resection. The incidence of lymph node metastasis is significantly higher in patients with subserosal invasion $>2 \mathrm{~mm}(63 \%)$ than in patients with invasion $<2 \mathrm{~mm}(27 \%)$ [13]. Some centres in the UK advocate a 3-month interval scan after incidental GBca in order to select patients that would benefit from major surgery [14].

In re-operative cases for $\mathrm{T} 2$ lesions, patients should be cautioned about the high possibility of not finding any residual disease in the resected specimen. In a review of ten years of reresection, residual tumour was found in all $\mathrm{T} 3$ tumours, but no residual hepatic disease was found in T2 tumours; overall 55 per cent of those undergoing re-resection had residual disease [15].

Finally, the controversial management of GBca is best described in an article by Kapoor et al. [16]. The author has discussed the management of GBca as western nihilism, Japanese aggressivism and the Indian "middle path".

\section{Conclusion}

In conclusion, tumour biology and stage, not extent of resection, is the most important predictor of outcome after resection for GBca. The goals of definitive resection should therefore be cholecystectomy with end bloc resection of invaded organs (most commonly the liver) around the tumour to provide reasonable margins and to resect regional lymph nodes. A randomized trial would be helpful to decide the extent of liver resection in gall bladder cancer.

\section{References}

1. Carriaga MT, Henson DE (1995) Liver, gallbladder, extrahepatic bile ducts and pancreas. Cancer 75(1): 171-190.

2. Wanebo HJ, Micheal PV (1993) Carcinoma gall bladder. J Surg Oncol 3(Suppl): 134-139.
3. Henson DE, Albores-Saavedra J, Corle D (1992) Carcinoma of the gallbladder. Histologic types, stage of disease, grade, and survival rates. Cancer 70(6): 1493-1497.

4. Chijiiwa K, Nakano K, Ueda J, Noshiro H, Nagai E, et al. (2001) Surgical treatment of patients with T2 gallbladder carcinoma invading the sub serosal layer. J Am Coll Surg 192(5): 600-607.

5. Kohya N, Miyazaki K (2008) Hepatectomy of segment $4 \mathrm{a}$ and 5 combined with extra-hepatic bile duct resection for T2 and T3 gallbladder carcinoma. J Surg Oncol 97(6): 498-502.

6. Valle JW, Borbat I, Khan SA, Huguet F, Gruenberger T, et al. (2016) Biliary cancer: ESMO Clinical practice guidelines for diagnosis, treatment and follow up. Ann Oncol 27(5): 28-37.

7. Wagholikar GD, Behari A, Krishnani N, Kumar A, Sikora SS, et al. (2002) Early gallbladder cancer. J Am Coll Surg 194(2): 137-141.

8. Ouchi K, Suzuki M, Tominaga T, Saijo S, Matsuno S (1994) Survival after surgery for cancer of the gallbladder. Br J Surg 81: 1655-1657.

9. Shirai Y, Yoshida K, Tsukada K, Wuto T, Watanabe H (1992) Early carcinoma of the gall-bladder. Eur J Surg 158: 545-548.

10. Abramson MA, Pandharipande P, Ruan D, S Gold JS, E Whang EE (2009) Radical resection for $\mathrm{T} 1 \mathrm{~b}$ gallbladder cancer: a decision analysis. HPB 11(8): 656-663.

11. Shimado H, Endo I, Togo S (1997) The role of lymph node dissection in the treatment of gallbladder carcinoma. Cancer 79(5): 892-899.

12. Wakai T, Shirai T, Yokohama N, Nagakura S, Watanabe H, et al. (2001) Early gall bladder cancer does not warrant Radical resection. British Journal of Surgery 88(5): 675-678.

13. Wakai T, Shirai Y, Yokoyama N, Ajioka Y, Watanabe H, et al. (2003) Depth of subserosal invasion predicts long term survival after resection in patients with T2 gallbladder carcinoma. Ann Surg Oncol 10(4): 447454.

14. Ausania F, Tsirilis T, White SA, French JJ, Jaques BC, et al. (2013) Incidental pT2-T3 gallbladder cancer after a cholecystectomy: outcome of staging at 3 months prior to a radical resection. HPB (Oxford) 15(8): 633-637.

15. Underwood TJ (2010) Gallbladder Cancer, The rationale for aggressive resection. In: Irving T, Colin DJ. (Eds,) Recent Advances in Surgery: 33, New Delhi: Jaypee Brothers Medical Publishers (P) Ltd pp. 67-72.

16. Kapoor VK (2007) Advanced gall bladder cancer: Indian "middle path". J Hepatobiliary Pancreat Surg 14(4): 366-373.
Your next submission with JuniperPublishers will reach you the below assets

- Quality Editorial service

- Swift Peer Review

- Reprints availability

- E-prints Service

- Manuscript Podcast for convenient understanding

- Global attainment for your research

- Manuscript accessibility in different formats

( Pdf, E-pub, Full Text, audio)

- Unceasing customer service

Track the below URL for one-step submission

https://juniperpublishers.com/online-submission.php 